\title{
Timeless Lessons from Dick Schulze
}

\author{
Catherine Buday (EIX) \\ Jon Eckhardt (University of Wisconsin-Madison)
}

\author{
KEYWORDS: Entrepreneurship, Management, \\ Leadership, Family Business, Learn From Leaders.
}

Best Buy Founder Dick Schulze built his empire through hard work, calculated risk, and a commitment to high standards of integrity and fairness. In his book "Becoming the Best," (https://www.amazon.com/Becoming-Best-Journey-

Passion-Perseverance/dp/061551037X) he outlines 10 major lessons he has learned through his decades as a successful entrepreneur. These lessons have withstood the test of time and remain great operating principles for business leaders.

\section{Listen to your customers}

"We are not involved in a game with our customer. Our goal is not to make them lose so we can win. We want them to win so we can win, too. Listening to them is necessary. And acting on what they say is essential."

\section{Know your competitors}

"We knew that the low-cost approach was not one we could win over the long term. Instead, we had to rewrite the rules somehow - break away from the pack of lookalike competitors. We saw that our customers wanted a very different experience than our competitors were offering....We knew that our competitors in the consumer electronics industry were not delivering that experience, and that gave us a huge opportunity."

\section{Perseverance pays}

"Entrepreneurship requires perseverance. It's certainly not for everybody. There's no rulebook. It's fraught with risk. There will be setbacks and disappointments and periods of uncertainly. To endure all that, you have to totally believe in your mission and be completely convinced that, over the long term, you're going to win."

\section{You must have a mentor}

"A mentor helps keep you grounded. A mentor helps you put your successes and your failures in perspective. When you start to believe you can do no wrong, your mentor can let you know just how wrong you are about that. When you come up against a rough issue, a mentor helps you think outside the box. Ideally, a mentor has traveled a similar path and can act as your guide."

\section{Hire strong people}

Entrepreneurs, and plenty of executives, are notorious for not hiring strong people. That's because we tend to believe that we've got all the answers, and we really don't want to be challenged as much as we need to be. Please, don't kid yourself. Every entrepreneur, every executive, and every manager needs strong people around them."

\section{Learn from mistakes}

"Because innovation involves trying new things, it has a higher failure rate than the execution of proven strategies does. That's why it's very important to create a culture that does not punish people for making mistakes. We view mistakes as an investment in employee training - assuming, of course, that the person and the company learn from the mistake and share what has been learned with others."

\section{Leverage your strengths}

"I believe that companies that fail to leverage the strengths of their people, in whatever way is necessary, get themselves in trouble. That's what happened at Circuit City, Highland, and Montgomery Ward. Their leaders thought they had all the answers and failed to pay attention to the people around them. At Best Buy, we have always tried to leverage the strengths of our people. When we succeed at doing so, the energy generated is amazing. Our people feel it and so do our customers."

\section{Be a good listener}

"Most people want to make a difference to their company and community. They want to play a useful 
role in achieving a successful outcome. They just need a chance to do so. Listen to them!"

\section{Create partnerships}

"Best Buy is a community made up of four main constituencies: employees, customers, vendors and shareholders. All four groups are important and necessary to the success of the company. All four must work together, in partnership, if Best Buy is to succeed. Everything we do, every decision we make, needs to create a winning outcome for all four constituencies. If we take advantage of one group over another, the relationship will not be sustainable...But if all four groups see that they are winning, the enterprise as a whole wins."

\section{Innovate continuously}

"Innovation is not an optional activity. It's not something we'll get around to when we have the time. It's not something we can outsource or leave to a consultant...Very few people can come up with big, brilliant, new ideas. Many of us can, however, come up with smart ideas for improvements, refinements, extensions and new applications for existing approaches." 